\title{
Myocardial Ischemia During Percutaneous Transluminal Coronary Angioplasty in Patients With Rich Collateral Circulation of the Target Lesion
}

\author{
Masato Watarai, MD; Fumimaro Takatsu, MD, FSCAI; \\ Hideki Horibe, MD; Masanobu Yanase, MD; \\ Kenji Takemoto, MD; Seiji Shimizu, MD; Yukio Shiga, MD
}

\begin{abstract}
Although it is commonly believed that ischemia does not develop during coronary intervention in patients with rich collateral circulation to the target vessel, ST changes are often observed. the study group comprised 40 consecutive patients who underwent elective percutaneous coronary angioplasty and who had rich collateral vessels to the target lesions. None had side branches in the target vessel that would be occluded by the angioplasty balloon. During the intervention, the 12-lead electrocardiogram was monitored for any change in the ST-T segment and 13 (32.5\%) showed significant ST changes. Of these, 3 had ST changes with every balloon inflation and the remaining 10 patients had ST changes with the second or subsequent inflations. Myocardial ischemia caused by balloon inflation is not uncommon during coronary angioplasty in patients with rich collaterals to the target vessel. The collateral circulation may stop functioning very early after improvement in the forward flow of the target vessel. (Circ J 2002; 66: 534-536)
\end{abstract}

Key Words: Collateral circulation; Myocardial ischemia; Percutaneous coronary angioplasty

I n patients with a total or subtotal occlusion, a rich collateral circulation develops from other vessels (Rentrop grade 3 or 2 collaterals) ${ }^{1}$ and it is believed that when such lesions are dilated, the patients do not feel any chest pain and there are no changes recorded on the electrocardiogram (ECG). However, we have occasionally noted patients with ST changes during coronary intervention despite a rich supply of collateral vessels and so we analyzed the cause of this phenomenon.

\section{Methods}

\section{Patients}

Among patients undergoing elective percutaneous coronary angioplasty (PTCA), we selected 40 fulfilling the following criteria: (1) the target vessel for PTCA was totally (20 patients) or subtotally (20 patients) occluded; (2) there was rich collateral circulation from other vessel(s) (Rentrop 3 or 2), and the source(s) of the collaterals did not have significant narrowing; (3) no akinesis or dyskinesis on left ventriculography of the area supplied by the target artery and no abnormal $\mathrm{Q}$ waves for the area corresponding to target artery; (4) no side branches arising within $2 \mathrm{~cm}$ of the target lesion; and (5) successful PTCA (final residual stenosis $<50 \%$ ).

\section{PTCA}

Long-acting diltiazem, long-acting isosorbide dinitrate, and aspirin were begun at least $24 \mathrm{~h}$ before the intervention

(Received October 12, 2001; revised manuscript received January 31, 2002; accepted February 20, 2002)

Department of Cardiology, Anjo Kosei Hospital, Anjo, Japan

Mailing address: Masato Watarai, MD, Department of Cardiology, Anjo Kosei Hospital, 12-38 Miyuki-hommachi, Anjo, Aichi 4468602, Japan and patients continued with their usual medications. After gaining arterial access, 100-150E of heparin was injected. In patients with complete occlusion, $5 \mathrm{~F}$ angiography catheters were engaged in the collateral donor vessel and 1-2 min before angioplasty, isosorbide dinitrate $(2.5-5 \mathrm{mg})$ was injected into the coronary artery with the target lesion. In almost all patients, the same diameter balloon was used for all inflations, which were of 90-120s duration and the balloons were inflated to 1-2 atm higher than the pressure at which the dumbbell sign vanished. The 12-lead ECG was monitored continuously during the procedure.

\section{Statistical Analysis}

The chi-square method was used for analysis and all data are expressed as mean \pm 1 standard deviation.

\section{Results}

The mean age of the patients was $59.3 \pm 10.5$ years and 30 patients were male. The target vessel was completely

Table 1 Clinical Characteristics of the Patient Group ( $n=40)$

\begin{tabular}{lc}
\hline \hline Age (years) & $59.3 \pm 10.5$ \\
F/M & $10 / 30$ \\
LAD/RCA/LCX lesions & $23 / 12 / 5$ \\
No. patients with totally occluded vessels & 20 \\
No. patients with non- $Q$ wave MI & 15 \\
Hypertension & 20 \\
Hyperlipidemia & 28 \\
Diabetes mellitus & 17 \\
Cigarette smoking & 15 \\
Obesity & 22 \\
\hline
\end{tabular}

Hyperlipidemia, total cholesterol $\geq 220$ and/or triglyceride $\geq 150$; Obesity, body mass index $\geq 25$. 
Table 2 Relationship Between Degree of Collateralization and Development of ST Changes During PTCA

\begin{tabular}{lccl}
\hline \hline & Rentrop 2 & Rentrop 3 & \\
\hline ST changes present & 8 & 5 & \\
ST changes absent & 9 & 18 & NS \\
\hline
\end{tabular}

Table 3 Patients Showing Significant ST Changes

\begin{tabular}{lcc}
\hline \hline Every inflation & $\begin{array}{c}\text { Only with second } \\
\text { inflation or later }\end{array}$ \\
\hline ST elevation & 2 & 8 \\
ST depression & 1 & 2 \\
Total & $3(7.5 \%)$ & $10(25 \%)$ \\
\hline
\end{tabular}

Table 4 Relationship Between the Degree of Stenosis and Development of ST Changes During PTCA

\begin{tabular}{lccc}
\hline \hline & $99 \%$ & $100 \%$ & \\
\hline ST changes present & 8 & 5 & \\
ST changes absent & 14 & 13 & NS \\
\hline
\end{tabular}

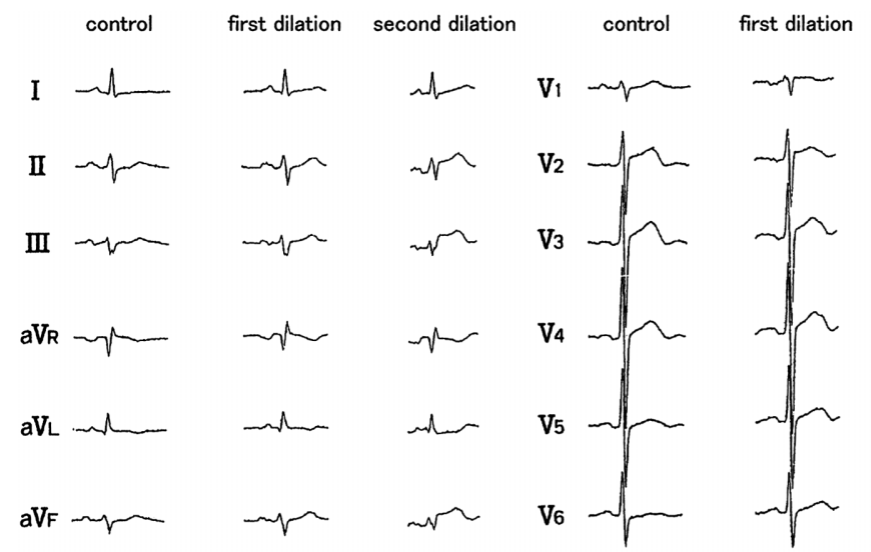

occluded in 20 patients $(50 \%)$ and subtotally occluded in 20 patients. Various risk factors (hypertension, hyperlipidemia, diabetes mellitus, cigarette smoking and obesity) were present in several patients (Table 1). The degree of collateral circulation was Rentrop grade 3 in 23 patients and grade 2 in 17 patients (Table 2). The target lesions were in the left anterior descending artery in 23 , right coronary artery (RCA) in 12 and left circumflex artery (LCX) in 5 patients. Thirteen patients (32.5\%) showed significant ST changes during the balloon inflation: 10 showed ST elevation and the remaining 3 had depression (those 3 had target lesions in the $\operatorname{LCX}(n=2)$ or in an atrioventricular branch of the RCA). The incidence of ST changes did not correlate with the degree of collateralization (Table 2) or with total or subtotal occlusion of the target lesion (Table 4). Of the 13 patients, 3 had ST changes with the first balloon inflation as well as with succeeding inflations and in the other 10 patients, the changes occurred only with the second and succeeding inflations (Figs 1,2).

\section{Discussion}

Many authors have reported less dramatic ST changes
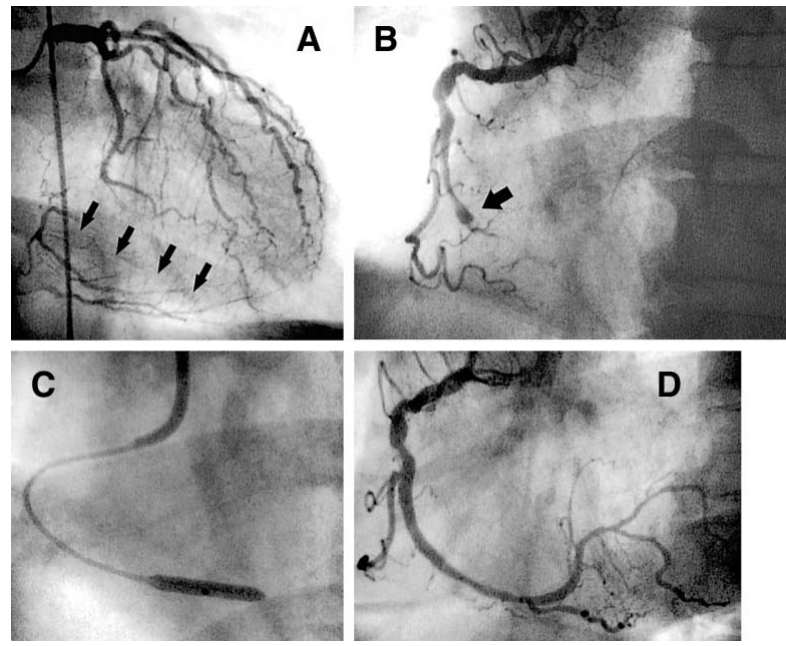

Fig 1. A 53-year-old male with stable effort angina. The right coronary artery (RCA) has a subtotal obstruction at segment 3 (A indicated by the arrow) and the left coronary artery (LCA) supplied rich collateral circulation to the distal segment of the RCA (B indicated by small arrow). Adequate dilatation of the RCA was obtained by PTCA $(\mathrm{C}, \mathrm{D})$.

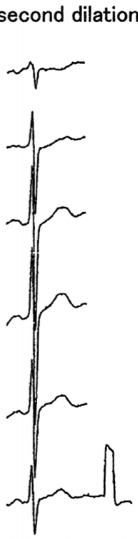

Fig 2. ST changes were not seen during the first balloon dilation, but significant ST elevations in the inferior leads were observed during the second balloon dilation.

(mainly elevation) and less left ventricular dysfunction during the second balloon inflation during angioplasty than during the first one and concluded that this ischemic preconditioning' reduces the extent of myocardial ischemia during the second and successive transient occlusions of the coronary artery,3 However, to the best of our knowledge, the phenomenon that we have described here has not been previously reported.

In the 3 patients who had ST changes during the first inflation, ischemia might have developed because of occluded distant side branches, despite the fact that we chose patients without side branches within $2 \mathrm{~cm}$ of the lesion. The balloons used were $2 \mathrm{~cm}$ in length in the maximally inflated portion; however, the ends of the balloons were tapered and may have occluded collaterals beyond the $2 \mathrm{~cm}$ 'safe zone'. In fact, 2 patients had very small branches approximately $2.0-2.5 \mathrm{~cm}$ distal to the target lesions. However, in the remaining 10 patients, this can only explain the ST changes that occurred after the first inflation. We hypothesize that flow through the rich collateral circulation decreases antegrade blood flow by opening occluded coronary arteries. This hypothesis is supported by the fact that in many patients in whom the contra-lateral arteries are 
opacified immediately after PTCA, the collaterals to the opened arteries have not vanished. Wemer et al found that in $36 \%$ of patients undergoing PTCA of a chronic total occlusion, the collateral coronary flow completely stopped at the end of the procedure 4

\section{Clinical Implications}

It is commonly believed that during angioplasty stenotic vessels receiving a rich supply of collaterals are not involved in ischemia because the collaterals maintain sufficient blood flow distal to the occlusion. However, our results suggest that collateral vessels might not function effectively after PTCA. In the setting of intervention in multivessel disease, it is standard procedure to first dilate the vessels with the collaterals and then dilate other vessels, including the arteries that give rise to the collateral vessels, based on the hypothesis that when a 'recipient' vessel closes during angioplasty, the myocardium supplied by the donor artery will not become ischemic because the collaterals supply retrograde flow. The results of our study suggest that at least in some patients, even a rich supply of collateral vessels becomes dysfunctional for several minutes, so their blood supply cannot be relied upon.

\section{References}

1. Rentrop KP, Cohen M, Blanke H, Phillips RA. Changes in collateral channel filling immediately after controlled coronary artery occlusion by an angioplasty balloon in human subjects. $J$ Am Coll Cardiol 1985; 5: $587-592$.

2. Deutsch E, Berger M, Kussmaul WG, Hirshfeld JW Jr, Herrmann HC, Laskey WK. Adaptation to ischemia during percutaneous transluminal coronary angioplasty: Clinical, hemodynamic, and metabolic features. Circulation 1990; 82: 2044-2051.

3. Crebier A, Korsatz L, Koning R, Rath P, Gamra H, Stix G, et al. Improved myocardial ischemic response and enhanced collateral circulation with long repetitive coronary occlusion during angioplasty: A prospective study. J Am Coll Cardiol 1992; 20: 578-586.

4. Wemer GS, Richartz BM, Gastmann O, Ferrari M, Lang K, Figulla HR. Recruitable and non-recruitable collateral circulation after successful recanalization of chronic total coronary occlusions (abstract). J Am Coll Cardiol 2000; 35(Suppl A): 64. 